Furthermore, Holmes lays down as one of the axioms that if an animal appears dull and off its feed as the result of the dosage with arsenic treatment must be suspended.

When dealing with animals in an advanced state of the disease it is not always an easy matter to determine whether the loss of appetite and dulness are due to the disease or to the treatment, and one may therefore be at a loss to know whether to push the treatment or to suspend it.

When an animal becomes very emaciated the appetite becomes very capricious and paroxysms very frequent or almost continuous. In such cases arsenic in the form of atoxyl would be indicated, but my supply of atoxyl was very limited, and did not enable me to ring the changes very frequently. Hence, I must admit I pushed on with the arsenic in bolus as much as possible, and did not suspend treatment unless very marked symptoms of arsenical poisoning were manifested. It was then usually too late, and the animal succumbed.

In the total of twelve shown as died there were five whose deaths were actually due to or precipitated by arsenical poisoning. If these were left out of account and not included as failures the percentage of recoveries would be very materially raised.

\title{
Conclusions.
}

Arsenic appears to have a specific action in a large percentage of cases, and clears the blood of trypanosomes.

In the light of the experiments of Holmes and others, there seems no reason to doubt that a permanent cure may be effected in a large percentage of cases. As the result of my own experiments, I provisionally claim 45 per cent. of cures, but prefer not to make a more definite assertion until these apparently cured cases have been under observation for a longer period.

The results so far justify a more extensive trial "in the field," more especially as no other drug has so far been proved to be of greater value. To obtain successful results one must be prepared for casualties due to individual susceptibility and overdosage.

\section{SOME OBSERVATIONS ON THE METHODS OF USING THE AGGLUTINATION TEST IN THE DIAGNOSIS. OF THE DISEASE IN BOVINES CAUSED BY THE. BACILLUS OF CONTAGIOUS ABORTION*}

\section{By H. R. SEDDON, B.V.SC., Veterinary Research Institute, University of Melbourne.}

The materials which may be examined with a view to the diagnosis of contagious abortion are :-

(I) Vaginal or uterine exudate after parturition.

(2) Fœtus or fotal membranes.

(3) Blood serum.

(4) Milk.

In animals which have recently aborted (I) and (2) are applicable, but in animals from which these have not been secured, or in others 
in which it is desirable to diagnose infection in the absence of abortion or at a time remote from the act of abortion, the most commonly used material is (3) serum. This is of especial value because of its being easily obtained from cows at all stages of the disease from shortly after infection onwards, also from male animals, proving that they are susceptible to infection, and from laboratory animals, such as guinea-pigs. In Australia the drawback is the difficulty of obtaining the serum from a whole herd in the country, where the dairymen would have to collect the samples.

It was because of this difficulty that investigations have been made as to the possible use of (4) milk. As far as I have been able to ascertain, this material, on account of its physical properties, has not been used to any extent for the agglutination test. In some respects milk itself is an unsatisfactory material, and for that reason whey, prepared by the artificial clotting of milk, has been used. Although these investigations are incomplete they furnish evidence strongly suggesting that it will be found satisfactory for diagnosis. Should this be so, milk, from its ease of collection, would be the ideal material for examination of lactating animals.

In the following pages will be found results of certain researches conducted on diagnosis from specimens of uterine exudate and of whey.

\section{I.-VAGINAL DISCHARGE CONTAINING UTERINE EXUDATE.}

The means available in the hands of the bacteriologist are :-

(I) Microscopical examination.

(2) Cultural examination.

(3) Inoculation of animals.

(4) Agglutination test, and

(5) Complement fixation test.

(I) Microscopical Examination.-To a person who is in the habit of frequently examining specimens containing the bacillus abortus the diagnosis presents no great difficulties, especially if the organisms are plentiful and typically arranged. On the other hand, there are met with in vaginal or uterine material bacteria which simulate more or less the bacillus abortus, and here the other tests help to confirm the diagnosis.

(2) Cultures.-For these to be satisfactory the material should be as free as possible from contamination by other organisms. In Australia a cow is frequently at grass when abortion takes place and may have aborted some days before the stockman sees her. The discharge in such cases is sure to be badly contaminated.

Also the discharge should obviously not contain any antiseptic. It sometimes happens that one is called upon to examine material from a cow which has been syringed out with lysol, the specimen smelling strongly of the antiseptic. For these reasons this method is of very limited application.

(3) Inoculation of Animals. - The remarks made about contamination and antiseptics under the last heading apply equally here. Nevertheless this method of diagnosis has been used here with success, guinea-pigs being used. Owing to the length of time before 
marked lesions develop, one resorts to the agglutination test of the blood serum of the guinea-pig to determine whether infection by the specific organism has taken place.

(4) Agglutination Test.-This has proved valuable in diagnosing a sample of exudate in which the microscopical findings were doubtful, and where, on account of great contamination, cultures were not obtained.

It has been found very delicate, as little as $0025 \mathrm{cc}$. of exudate causing agglutination. In one of these positive cases the agglutinating titre of blood serum, secured sixteen days later than the exudate and seventeen days after abortion, gave an exactly similar agglutinating titre to the exudate (see Cow 2, "Bluey.")

Further, exudate may be kept until it is fairly swarming with bacteria and yet show little loss of agglutinant action. Also exudate diluted with carbolised saline (Io per cent. of exudate in saline containing 5 per cent of carbolic acid).

Exudate from a healthy cow which calved at the Institute was tested, and even in an amount of $25 \mathrm{cc}$. failed to give any agglutination.

(5) Complement Fixation Test.-No opportunity has presented itself of applying this test to exudate, but judging from the results with the agglutination test on this material there seems to be no reason why it should not be of use for diagnostic purposes. ${ }^{1}$

\section{Details of Cows.}

(I) Normal Core.-This animal was kept at the Institute in connection with another experiment. She calved after the usual signs of on-coming parturition, the offspring being of full size and vigorous.

Exudate secured the day she calved gave no agglutination with $\cdot 25 \mathrm{cc}$.

Whey from milk taken eleven days after calving gave a positive agglutination with $25 \mathrm{cc}$. but a negative with $05 \mathrm{cc}$.

(2) Cow, "Bluey."-Detailed history not available. Aborted on Ist September I9I3.

Exudate, in appearance typical of the disease, was secured from the vagina next day. It was tested four days later and agglutinated at $I 5 \mathrm{cc}$, this being the smallest quantity used. Twelve days later the end-point was determined to be $0025 \mathrm{cc}$., the material used in this test having been left in the bottle and being now fairly putrid. At the same time material which had been diluted with carbolised saline twelve days ago now gave a reaction with $005 \mathrm{cc}$.

Microscopical Examination of Exudate showed long chains of bacilli, streptococci, and also some clumps of bacilli the size of bacillus typhosus. Smears from placental membrane showed streptobacilli and streptococci as above. Neither specimen showed bacilli which could be definitely recognised as the bacilli of contagious abortion.

Cultures of the bacillus abortus were not obtained, the tubes being overgrown by the other organisms present.

\footnotetext{
1 An opportunity has since presented itself of testing, by the complement fixation method, a sample of vaginal exudate from a cow which had recently aborted. The result was positive, thus showing that this test may also be employed for diagnosis as is suggested above.
} 
(3) Cow, "Baptist."-Aborted on 22nd June I9I4.

Exudate secured from the vagina two days later gave agglutination with $0025 \mathrm{cc}$.

Microscopical Examination of Exudate showed numerous organisms morphologically like bacillus abortus.

Inoculation of Animals.-Guinea-pig 488 was inoculated subcutaneously with exudate, and its serum tested nine days later gave no agglutination; forty days after inoculation a positive agglutination was obtained with $I 5$ cc. of serum; seventy-six days after inoculation $0025 \mathrm{cc}$. of serum gave a positive agglutination; ninety-five days after inoculation the animal was killed.

Post-mortem Examination.-Animal in good condition and all organs apparently normal except the spleen, which showed a nodular appearance externally and on section numerous very small greyish foci which looked rather more like enlarged and prominent Malpighian bodies than foci of necrotic material. On smears no organisms could be detected.

Guinea-pig 489, inoculated intraperitoneally with exudate, was tested forty days after inoculation, when the serum gave a positive agglutination reaction.

(4) Cow, "Garfish."-Calved 5th July I9I4, not being due till the I 7 th of the same month, but the owner remarks "calf full size but dead."

Exudate was secured two days after parturition and gave no agglutination when tested, using $05 \mathrm{cc}$.

Microscopical Examination of Exudate failed to demonstrate the presence of bacillus abortus and cultures gave negative results.

Animals Inoculated.-Guinea-pig 49I, inoculated intraperitoneally with exudate, was tested three times (the last test I 3 days after inoculation), but the serum giving no agglutination. Guinea-pig 492, inoculated subcutaneously with exudate, when tested one month after inoculation gave a similar negative result.

Whey from milk collected eight days after calving gave a negative result with $05 \mathrm{cc}$.

\section{II.-TECHNIQUE EMPLOYED.}

In the following pages details of the technique employed in the use of all the materials examined are given with a view to a standardisation of the test in the hands of different workers, so that the interpretation and comparison of results may be possible and accurate.

\section{(a) The Use of Whey and the Value of the Method.}

That the specific agglutinins of the bacillus abortus may occur in milk has been mentioned by M'Fadyean and Stockman (I) in the Appendix to Part I. of the Departmental Committee's Report, p. 28, where they say "We also found that the milk of an animal which had aborted possessed agglutinating properties up to $I$ in 25 , but, owing to the opacity caused by the addition of milk to a culture, milk is unsuitable for testing purposes." Whether this product has been used at all in diagnosis I am not aware.

It would appear that if milk could be used it would be advantageous owing to the ease of securing specimens, but as milk, even 
diluted, is unsatisfactory on account of its physical properties, experiments were made with whey. The whey was obtained by clotting milk with lactic acid, the technique being as follows :-

To $9 \mathrm{cc}$. of milk I cc. of a Io per cent. aqueous solution of lactic acid is added and mixed. The coagulated milk is then filtered through either cotton-wool and filter paper or filter paper alone, the latter method being usually applied.

The whey is then diluted, one part to nine parts of carbolised saline (acid. carbol. liq. '5, sod. chlor. 85 , water 100) to form the basal dilution $I$ in $I 0$ and incubated over night. Incubation and subsequent filtration are found necessary, as otherwise there may be a deposit of albuminous material which, though unlike the typical deposit of agglutinated organisms, is not desirable, since it may lead to confusion in reading the results.

With the diluted, incubated, and filtered whey four tubes, each receiving $5 \mathrm{cc}$. of standard emulsion, are put up containing the following amounts of the basal dilution of whey ( $\mathrm{I}$ in IO).

$$
\begin{array}{cclll} 
& \mathrm{A} & \mathrm{B} & \mathrm{C} & \mathrm{D} \\
& \mathrm{I} \cdot \mathrm{O} & \cdot 2 & \cdot \mathrm{I} & \cdot 05 \mathrm{cc} \text {. } \\
\text { (representing } & \cdot \mathrm{I} & \cdot \mathrm{O} 2 & \mathrm{OI} & \cdot 005 \mathrm{cc} \text { of pure whey) }
\end{array}
$$

As a control, I cc. of whey is put in a tube without any emulsion. Carbolised saline is then added till the amount of liquid in each tube is approximately $\mathrm{I}^{\circ} 5 \mathrm{cc}$.

Thus the series of tubes contain :-

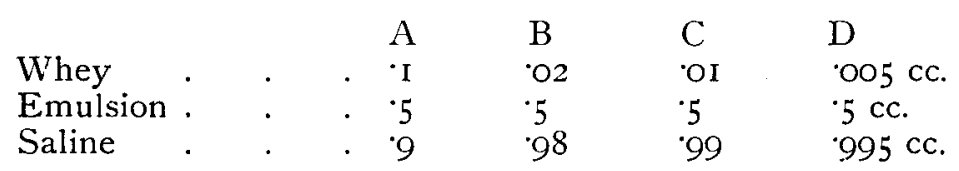

The tubes are then shaken and put in the incubator till next day, when the results are read. Further incubation shows little alteration, but a tube showing "partial" agglutination, i.e., slight deposit with no "clearing" of the supernatant fluid, at the end of eighteen to twenty-four hours may be complete at the end of thirtysix to forty-eight hours.

Whey from milk which had been kept twenty days at room temperature and had clotted naturally has also been tested, and it was found that this bacterially produced whey exhibited the same titre as the whole milk.

A large number of experiments with whey have been performed, but as yet no conclusion has been come to as regards the limiting titres upon which a diagnosis may be made. It has been found that the agglutinins in whey increase and decrease in much the same manner as they do in blood serum. The work to date has been chiefly among cows on a property where the disease has been in existence for a number of years, but where the abortions, since the investigations commenced, have been very few-not sufficient to warrant a definite opinion as to the comparative value of whey versus serum. Sufficient has been done, however, to warrant investigation of the value of whey as a material for diagnosis by other workers. 


\section{(b) Collection of Serum from Cattle and Guinea-pigs. Occurrence of} the Agglutinins in the Blood of Steers.

Cattle.-Undoubtedly the most satisfactory method of obtaining serum in large quantities is by bleeding from the jugular vein, but, as this method takes some time and often necessitates the casting of the animal, another and simpler method is required where only small quantities of blood sufficient for diagnostic purposes are required.

It has been found that such may be best obtained from the small artery which runs alongside the vein extending along the centre of the dorsum of the ear. This vein is the most prominent and is easily found. The hair is clipped off and an incision is made across the vein and the artery at a point about mid-way between the tip and the base of the ear. The artery may not be cut at the first incision as it usually lies underneath the vein, and a second rather free incision may be necessary. From this the blood spurts or drips freely, and 5 to Io cc. can be collected in a test-tube. The blood is allowed to clot, the clot loosened from the sides of the tube for about two-thirds of its attachment, and the tube inverted in a conical urine test-glass. After allowing this to stand for some hours the serum may be collected free from corpuscles.

Guinea-pigs. - The following method has been found satisfactory for obtaining small quantities of serum for diagnostic purposes.

Centrifuge tubes are put up containing 2 cc. of citrated carbolised saline (sod. chlor. 85 , sod. cit. I, acid. carb. liq. $\cdot 5$, water 100). The margin of the ear of the guinea-pig is then incised with the scissors and held dependent. There is a small artery in this region from which, if it has been cut, the blood drips freely. Six drops of blood are collected in the prepared tubes. If we assume that six drops of blood are equal to $3 \mathrm{cc}$. then we should have about $2 \mathrm{cc}$. of serum in each tube, or a dilution of $\mathrm{I}$ in $\mathrm{IO}$.

The tubes are shaken and centrifugalised, and the supernatant fluid is pipetted off and tested in various quantities. Though not quite accurate this method is sufficiently so for determining whether the animal is harbouring the bacilli, as, for example, those animals inoculated with vaginal exudate or milk from suspected cows. Healthy non-inoculated guinea-pigs have invariably given a negative reaction, even with ' $\mathrm{I}$ cc. of pure serum (i.e., I cc. of the citrated saline mixture), whereas some of our reacting guinea-pigs have given an agglutinating titre of $005 \mathrm{cc}$. and in one case of $0005 \mathrm{cc}$.

\section{Examination of the Blood of Steers.}

Because of the large number of cows which give a positive agglutination reaction, it is important to determine whether agglutination of the contagious abortion bacillus is brought about by normal ox serum, and if at all to what extent. With a view to obtaining information on this point experiments have been conducted with the serum of male and of female animals.

The following experiments have been made with the serum of steers. The animals were for human consumption and the blood was taken, immediately upon slaughter at the abattoirs, into a 
bottle containing a small quantity of strong (20 per cent.) citrate solution. The serum was obtained by centrifugalising and tested as follows :-

Basal dilutions were made containing I of serum to 9 of carbolised saline; the amount of standardised emulsion used in each tube was $.5 \mathrm{cc}$.

Results.

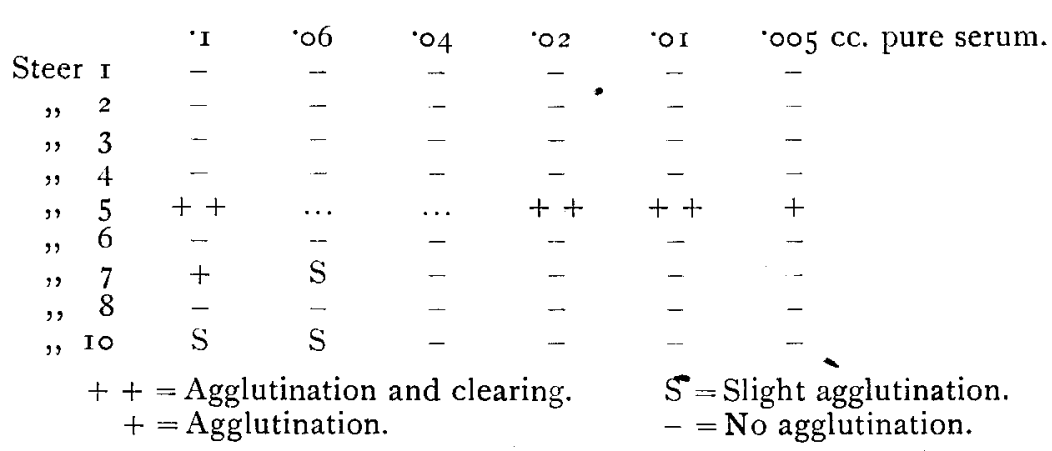

From the above it will be seen that with the exception of Steer 5 no animal gave a positive reaction with less than $I \mathrm{cc}$. of pure serum, and only one a definite agglutination with that amount. With regard to the " $S$ " readings, as mentioned elsewhere, we do not count these as positives, as the amount of agglutination is extremely small - only perceptible on very careful naked eye examination.

The serum of the positive steer (5) was also tested by the complement fixation method and again gave a positive reaction.

\section{(c) Standardisation of the Bacterial Emulsion.}

In the description of the technique adopted by other workers there is a remarkable absence of detail as to the concentration of the bacterial emulsion.

Although Mohler and Traum (2) use a method of standardising bacterial emulsion ("agglutinating fluid") by comparing it with " the old titred agglutinating fluid," but how this "old agglutinating fluid" itself was standardised they do not say, nor do they indicate what it was like in appearance.

M'Fadyean and Stockman (3) prepare "an emulsion of greater turbidity than is ultimately required," and dilute it "until, when viewed in one of the small tubes employed for the tests, it is faintly hazy in appearance."

In this laboratory a method based upon comparison of the emulsion to be employed with a suspension of barium sulphate has been used, the idea being embodied from the "Nephelometer" of M'Farland (4).

For the test the following solutions are made: a I per cent. solution of barium chloride in distilled water, and a I per cent. solution of sulphuric acid in water. Three cc. of the barium solution is then mixed with $97 \mathrm{cc}$. of the acid solution, shaken, and allowed to stand to come to a state of chemical equilibrium.

The bacillus abortus is sown on agar in Roux flasks and incubated 
for two or three days, the water of condensation being run over the surface daily, so as to get a good growth over the whole surface. Twenty cc. of carbolised saline (acid. carb. liq. 5, sod. chlor. 85 , water 100 ) is then added to the flask and the growth washed off, shaken thoroughly, and passed twice through filter paper. Dilutions of this suspension, or "emulsion," as it is generally called, are then made with carbolised saline as follows: I cc. of emulsion and I cc. of carbolised saline, I cc. of emulsion and $2 \mathrm{cc}$. of carbolised saline, and so on up to $\mathrm{I}$ cc. of emulsion and $\mathrm{IO} \mathrm{cc}$. of carbol saline. These suspensions are the fluids to be compared with the barium sulphate mixture.

To compare, the barium sulphate mixture is thoroughly shaken, and a small tube of about $\mathrm{I} \mathrm{cm}$. calibre filled with the fluid, the fluids to be tested being placed in similar sized tubes, and comparisons. made over printed paper. This barium suspension is our standard of opacity for emulsion (Standard X).

Supposing the tube which exactly approximates the opacity of the barium mixture is that tube which contains I $c c$. of thick emulsion and $6 \mathrm{cc}$. of carbolised saline, then this tube is of the proper standard, and is called "Standard X." The whole of the emulsion may then be diluted down with carbolised saline to the proper strength or kept as thick emulsion, the standard being known. In the case instanced the thick emulsion may be termed " $7 \mathrm{X}$," thereby denoting that it requires diluting to seven times its volume, i.e., adding six times its volume of carbolised saline, to prepare a standardised emulsion "X."

In our tests, in which we make the total volume of fluid in the tube up to $1.5 \mathrm{cc}$., we use $5 \mathrm{cc}$. of this standard emulsion " $\mathrm{X}$ " in each tube.

III-QUANTITATIVE FACTORS IN THE AGGLUTINATION REACTION.

\section{(a) Not Simply a Matter of Dilution, but a Quantitative Reaction.}

An unfortunate terminology has crept into descriptions of agglutination methods-probably a relic from the descriptions of the so-called Widal reaction with the serum of typhoid patients-in which frequent use is made of the term "dilution" to express the amounts of serum (or other diagnostic fluid) necessary to bring about agglutination.

The following experiments show that the sensitiveness of the reaction is to be measured by accurate determination of the minimal quantity of serum employed-in other words, it is not simply a matter of dilution, but a quantitative reaction.

Experiments. - To determine whether: (I) The relation of the quantity of pure serum to the quantity of fluid in a tube (i.e., degree of dilution); or (2) the amount of pure serum in the tube is the determining factor in agglutination of a particular serum.

Serum collected from a cow thirteen days previously was used, a basal dilution of $\mathrm{I}$ of serum to 49 of carbolised saline being made. ( $\mathrm{I}$ in 50 ).

The emulsion was standardised in accordance with the usual method, and found to be of a Standard " Io X." 
Set $I .(a)$.

Ten tubes were put up as follows :-

\begin{tabular}{|c|c|c|c|c|c|c|c|c|c|c|c|}
\hline & & $\mathbf{A}$ & $\mathrm{B}$ & $\mathrm{C}$ & D & $\mathrm{E}$ & $\mathrm{F}$ & G & $\mathrm{H}$ & $\mathrm{J}$ & $\mathbf{K}$ \\
\hline Serum ( 1 in 50$)$ & . & $\begin{array}{l}\text { cc. } \\
1 \cdot 0\end{array}$ & $\begin{array}{l}\text { cc. } \\
1 \cdot 0\end{array}$ & $\begin{array}{l}\text { cc. } \\
1 \cdot 0\end{array}$ & $\begin{array}{l}\text { cc. } \\
1 \cdot 0\end{array}$ & $\begin{array}{l}\text { ec. } \\
1 \cdot 0\end{array}$ & $\begin{array}{c}\text { cc. } \\
0.5\end{array}$ & $\begin{array}{l}\text { cc. } \\
0.5\end{array}$ & $\begin{array}{l}\text { cc. } \\
0.5\end{array}$ & $\begin{array}{l}\text { cc. } \\
0.5\end{array}$ & $\begin{array}{l}\text { cc. } \\
0.25\end{array}$ \\
\hline Carbolised saline & - & $0 \cdot 0$ & 0.5 & $1 \cdot 0$ & 15 & $2 \cdot 0$ & $1 \cdot 25$ & $1 \cdot 5$ & $2 \cdot 0$ & $2 \cdot 5$ & 175 \\
\hline Total volume. & . & $1 \cdot 0$ & 15 & $2 \cdot 0$ & $2 \cdot 5$ & $3 \cdot 0$ & $1 \cdot 75$ & $2 \cdot 0$ & 25 & $3 \cdot 0$ & $2 \cdot 0$ \\
\hline $\left.\begin{array}{l}\text { Relationship of } \\
\text { serum to fluid }\end{array}\right\}$ & $1 \mathrm{in}$ & 50 & 75 & 100 & 125 & 150 & 175 & 200 & 250 & 300 & 400 \\
\hline
\end{tabular}

Of each of these dilutions I cc. was put in a tube, and the tubes similarly lettered, so that the amounts of pure serum in these tubes were :-

$$
\begin{array}{cccccccccc}
\mathrm{A} & \mathrm{B} & \mathrm{C} & \mathrm{D} & \mathrm{E} & \mathrm{F} & \mathrm{G} & \mathrm{H} & \mathrm{J} & \mathrm{K} \\
\cdot \mathrm{O} 2 & \text { OI2 } & \text { OI } & \cdot 008 & \cdot 006 & \cdot 0056 & 005 & \cdot 004 & 003 & \cdot 0025 \mathrm{cc} .
\end{array}
$$

Emulsion ( 05 cc. Standard IO X) was then added to each tube, and the tubes were incubated till next day, when readings were taken.

Results.-A, B, and C, agglutination and clearing; D and $\mathrm{E}$, agglutination; $F$, slight agglutination; $G, H, J$, and $K$, no agglutination.

$$
\text { Set } I .(b) \text {. }
$$

Another ten tubes were put up similarly to above (Set I. (a)), but with ' I cc. of emulsion (i.e., double quantity) added.

Results.-A, agglutination and clearing. No agglutination in other tubes.

Note-In these tubes actual dilution of serum in total fluid (neglecting the small amount added with the emulsion) was the outstanding test.

$$
\text { Set } I I .(a) \text {. }
$$

Serum and carbolised saline were placed in tubes as in Set I., but the bacterial emulsion was added to the whole of the fluid in each tube (not to I cc. of each dilution).

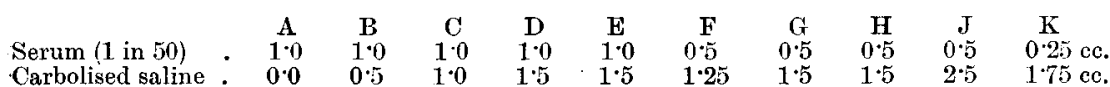

The actual dilution of the serum in these tubes therefore is the same in both tests (Sets I. and II.), but the actual amount of serum in each tube is not the same in correspondingly lettered tubes in each test (see Table I.).

Emulsion added ( ${ }^{\circ} 5 \mathrm{Cc}$ ), and tubes incubated as in Set I. (a).

Result.-Agglutination and clearing in all tubes from $A$ to $J$ inclusive. No agglutination in $\mathrm{K}$.

$$
\text { Set } I I .(b) \text {. }
$$

Tubes put up similarly to last set (Set II. (a)), but with I cc. of emulsion (double quantity) added. 
Result.-Agglutination and clearing in A, B, C, D, and E. No. agglutination in other tubes.

Control tubes were put up containing (I) serum and saline, and (2) emulsion and saline.

\section{Note on Readings.}

"Agglutination" is to be interpreted as a definite macroscopic aggregation of organisms into clumps deposited either at bottom of tube, or at bottom and along sides of tubes.

"Clearing" where the supernatant fluid is free, to the naked eye, of suspended organisms, i.e., agglutination and sedimentation.

"Slight" where there is a trace of agglutination deposit-not what one might with confidence call a definite agglutination. These "slights" are read as negative agglutinations in considering the agglutination titre of a serum.

TABLE I.

\begin{tabular}{|c|c|c|c|c|c|c|c|c|c|}
\hline \multicolumn{3}{|c|}{ SET I. } & \multirow{2}{*}{ 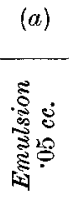 } & \multirow{2}{*}{ 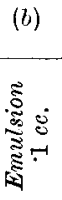 } & \multicolumn{3}{|c|}{ SET II. } & \multirow{2}{*}{ 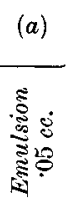 } & \multirow{2}{*}{ 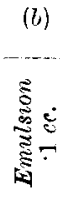 } \\
\hline Tube. & $\begin{array}{l}\text { Awount of } \\
\text { Serum. }\end{array}$ & Dilution. & & & Tube. & $\underset{\text { Serum. }}{\text { Amount of }}$ & Dilution. & & \\
\hline $\mathrm{A}$ & $\stackrel{c c .}{.}$ & 1. in 50 & ++ & + & A & $\begin{array}{l}\text { cc. } \\
.02\end{array}$ & 1 in 50 & ++ & ++ \\
\hline B & $\cdot 012$ & 1 in 75 & ++ & - & B & $\cdot 02$ & 1 in 75 & ++ & $t+$ \\
\hline$O$ & $\cdot 01$ & 1 in 100 & $+t$ & - & $\mathbf{C}$ & $\cdot 02$ & 1 in 100 & $+t$ & ++ \\
\hline D & $\cdot 008$ & 1 in 125 & + & - & $\mathbf{D}$ & $\cdot 02$ & 1 in 125 & ++ & ++ \\
\hline $\mathbf{E}$ & $\cdot 006$ & 1 in 150 & + & - & $\mathbf{E}$ & $\cdot 02$ & 1 in 150 & ++ & ++ \\
\hline $\mathbf{F}$ & 0056 & 1 in 175 & $\mathbf{S}$ & - & $F$ & $\cdot 01$ & 1. in 175 & ++ & - \\
\hline $\mathrm{G}$ & $\cdot 005$ & 1 in 200 & - & - & G & $\cdot 01$ & 1 in 200 & ++ & - \\
\hline $\mathbf{H}$ & $\cdot 004$ & 1 in 250 & - & - & $\mathbf{H}$ & $\cdot 01$ & 1 in 250 & ++ & - \\
\hline $\mathbf{J}$ & $\cdot 003$ & 1 in 300 & - & - & $J$ & 01 & 1 in 300 & ++ & - \\
\hline $\mathrm{K}$ & $\cdot 0025$ & 1 in 400 & - & - & $\mathbf{K}$ & $\cdot 005$ & 1 in 400 & - & - \\
\hline & $\begin{array}{r}++= \\
+=\end{array}$ & lutinatio & and $c$ & aring & & $\begin{aligned} S & =\text { Slight } \\
- & =\text { No ag }\end{aligned}$ & $\begin{array}{l}\text { gglutinatio } \\
\text { atination. }\end{array}$ & & \\
\hline
\end{tabular}

(I) Using the same quantity of emulsion in each tube, tubes. possessing the same dilution (but different quantities) of serum do not furnish parallel results. (Compare Set I. (a) with Set II. (a), Set I. (b) and Set II. (b), etc.)

(2) Using the same quantity of emulsion in each tube, tubes containing the same quantity of serum do furnish parallel results.

(3) The agglutination titre varies with the quantity of emulsion used, for, as is evident in the Table (I.): (a) with 05 cc. of concentrated emulsion (IO $\mathrm{X}$ ) the minimum amount of this serum which will produce agglutination is $006 \mathrm{cc}$. ; $(b)$ with $\cdot \mathrm{I}$ cc. of concentrated emulsion ( $\mathrm{IO} X$ ) the minimum quantity of serum required is $\mathrm{O} 2 \mathrm{cc}$. 
Experiments were then carried out to test the effect of dilution on an agglutination system :-

Tubes were put up containing :-

\begin{tabular}{|c|c|c|c|c|}
\hline & A & $\mathrm{B}$ & C & $\mathrm{D}$ \\
\hline Pure serum & .02 & 015 & OOI & $.005 \mathrm{cc}$ \\
\hline Emulsion ( Io X.) & .05 & 05 & .05 & O $55 \mathrm{cc}$ \\
\hline
\end{tabular}

Test I.-Volume of fluid in each tube made up with carbolised saline to I cc.

Test 2.-Volume of fluid in each tube made up to $2.5 \mathrm{cc}$.

Results, both tests.- $\mathrm{A}$ and $\mathrm{B}$, agglutination and clearing; C, agglutination; D, no agglutination.

Test 3.-A tube was put up containing $02 \mathrm{cc}$. pure serum and $\mathrm{O} 5$ cc. emulsion ( Io X) and carbolised saline added up to $20 \mathrm{cc}$.

Result.-Agglutination.

These tests show that the dominating factor is the quantity of serum in each tube and not the degree of dilution. Of course, if equal quantities of each dilution be taken for testing the quantity of serum in the tube will vary as the dilution, as is shown in Set I. (a). On the other hand, in the practical application of the agglutination test the important figure is what may be termed the "end-point," i.e., the smallest quantity of serum which will produce agglutination with a standard quantity of emulsion. The necessity therefore arises for taking for all tests an exactly similar quantity of diluted serum, and hence it is advisable to refer to the agglutinating titre of a serum as "so many cubic centimetres of serum," and not as "up to a dilution of such and such." For the statement of the dilution to be of any guide to other workers, this must be supplemented by a statement referring not only to the actual quantity of emulsion used, but of the actual amount of diluted serum used.

Adopting the method suggested, i.e., the statement of the exact quantity of serum used, the amount of emulsion used is the only supplementary factor required to be known, for, as is shown by these experiments and by the following section, the amount of emulsion markedly and in a regular manner affects the agglutination titre.

\section{(b) Infuence of Quantity of Emulsion on Agglutination. Also a Note on a Peculiarity of Agglutination.}

As is indicated in the experiments in sub-section (a) of Section III. of this paper, the quantity of emulsion present in a tube in which there is a certain definite amount of serum, or, in other words, the proportion between the amount of emulsion and the amount of serum, has a bearing on whether the particular quantity of serum will show agglutination of the bacilli or not. The tests $I(a)$ and I (b) (see Conclusion 3, p. 29) showed that, whereas with $05 \mathrm{cc}$. of emulsion (Standard Io $\mathrm{X}$ ) agglutination occurred with quantities of serum varying from $006 \mathrm{cc}$. up, with I $\mathrm{cc}$. of the same emulsion the smallest quantity of serum to give agglutination was $\mathrm{O} 2 \mathrm{cc}$.

To further elucidate this relationship a large number of tubes, with varying proportions of emulsion and serum, were put up as indicated in the table (Table II.) in which the results are also shown. On account of the wide range in quantities over which the experiment was made, various concentrations of serum and of emulsion were used in actually making the test. 
These basal dilutions were :-

Of Serum. - I in 5, I in 50, and I in 500 .

Of Emulsion.-A stàndard suspension "X," and also one standardised to Io $X$, i.e., ten times as strong.

The quantities of emulsion used are stated throughout the table in terms of Standard $\mathrm{X}$ emulsion, but for those tubes shown in the table as containing $I$ cc. and over of Standard $X$ emulsion, the 10 $\mathrm{X}$ emulsion was used, the amounts of this (Standard $10 \mathrm{X}$ ) that were put in being $\cdot 1, \cdot 2, \cdot 4, \cdot 6, \cdot 8$, and $I$ cc. respectively. Similarly, in regard to the serum, for those tubes shown as containing $\mathrm{O}_{4} \mathrm{cc}$. of serum and over the basal dilution of $I$ in 5 was used, the quantities of this that were put in being $\cdot 2,4,6, \cdot 8$, and $I$ cc. respectively; for those tubes shown as containing from ${ }^{\circ} \mathrm{OO} 2$ to ${ }^{\circ} \mathrm{O} 2 \mathrm{cc}$. of serum a basal dilution of $I$ in 50 was used, the quantities being $I, \cdot 2, \cdot 4, \cdot 6,8$, and I cc. respectively; for those tubes shown as containing less than 002 cc. of serum a basal dilution of $\mathrm{I}$ in 500 was used, the quantities of this that were put in being $\cdot 8, \cdot 6,4, \cdot 2$, and $1 \mathrm{cc}$. respectively.

In each tube the total quantity of fluid was made up to (approximately) 2 cc. Control tubes were put up, (I) of serum, and (2) of emulsion, and in each case remained unchanged.

TABLE II.

\begin{tabular}{|c|c|c|c|c|c|c|c|c|c|c|c|}
\hline \multirow{2}{*}{$\begin{array}{l}\text { Serum, cc. of } \\
\text { Pure Serum. }\end{array}$} & \multicolumn{11}{|c|}{ Emulsion, ce. of Standard X. } \\
\hline & 10 & 8 & 6 & 4 & 2 & 1 & 8 & 6 & $\cdot 4$ & $\cdot 2$ & $\cdot 1$ \\
\hline$\cdot 2$ & ++ & ++ & $+t$ & ++ & + & + & $+u$ & ++ & ++ & ++ & ++ \\
\hline$\cdot 16$ & ++ & $+t$ & ++ & ++ & ++ & + & + & ++ & ++ & ++ & ++ \\
\hline$\cdot 12$ & + & + & $+t$ & ++ & ++ & + & + & + & ++ & $+t$ & ++ \\
\hline 08 & - & + & + & ++ & $+t$ & $+t$ & $+u$ & + & + & $+t$ & ++ \\
\hline .04 & - & - & + & + & ++ & ++ & ++ & $+u$ & + & + & ++ \\
\hline$\cdot 02$ & - & - & - & - & + & ++ & ++ & ++ & ++ & ++ & ++ \\
\hline 016 & - & - & - & - & - & + & ++ & ++ & ++ & ++ & +1 \\
\hline .012 & - & - & - & - & - & + & + & ++ & $+t$ & ++ & +4 \\
\hline 008 & - & - & - & - & - & - & + & + & $+t$ & ++ & ++ \\
\hline .004 & - & - & - & - & - & - & - & - & + & $t+$ & ++ \\
\hline .002 & - & - & - & - & - & - & - & - & - & + & ++ \\
\hline$\cdot 0016$ & - & - & - & - & - & - & - & - & - & - & - \\
\hline$\cdot 0012$ & - & - & - & - & - & - & - & - & - & - & -- \\
\hline .0008 & - & - & - & - & - & - & - & - & - & - & - \\
\hline .0004 & - & - & - & - & - & - & - & - & - & - & - \\
\hline .0002 & - & - & - & - & - & - & - & - & - & - & - \\
\hline
\end{tabular}

$++=$ Agglutination and clearing.

$+u=$ Agglutination-supernatant fluid nearly cleared.

$+=$ Agglutination-supernatant fluid not cleared.

$-=$ No agglutination. 
These tests show that the quantities of emulsion and of serum combining to produce agglutination bear a direct relationship to one another. With other than these proportions an excess of one or other will be left over. The result is particularly striking if one takes the extreme results "the agglutination and clearing" end. point, shown by ++ ) which are found to form a straight line when plotted as a graph.

It will also be noted that this arrangement is kept up over the whole length of the series.

One further point is evident from Table II, viz., that there is a partial inhibition with certain proportions of emulsion and serum, as may be seen from looking at the tubes containing $2 \mathrm{cc}$. emulsion and $\cdot 2 \mathrm{cc}$. serum; I cc. emulsion and $\cdot 2, \cdot \mathrm{I} 6$, and $\cdot \mathrm{I} 2 \mathrm{cc}$. serum ; $8 \mathrm{cc}$. emulsion and $\cdot 2, \cdot 16, \cdot 12$, and $\cdot 08 \mathrm{cc}$. serum; $6 \mathrm{cc}$. emulsion and $\cdot 12$, $\circ 8$, and 04 cc. serum; 4 cc. emulsion and 08 and 04 cc. serum; and $\cdot 2 \mathrm{cc}$. emulsion and $\cdot 04 \mathrm{cc}$. serum.

Comparing these with tubes lower down in the same column, where the amount of serum is less, we find that where the smaller quantities of serum are used there is again complete agglutination and clearing. Further, where larger quantities of serum are used there is also agglutination and clearing, the inhibition thus being apparently zonary. This is well seen in the columns of tubes containing $\cdot 8, \cdot 6, \cdot 4$, and $2 \mathrm{cc}$. of emulsion.

Further, in the table this zone of inhibition is found to lie approximately parallel to the agglutination end-point; it seems, therefore, as if there were at least two maxima of agglutination for a given quantity of serum varying with the quantity of emulsion, and, between these two maxima, the zone of inhibition.

A peculiar agglutination phenomenon similar to this had been noted before with serum from the same animal.

In this previous test the same amount of emulsion was used in each tube, and the following quantities of serum were placed in tubes:-

$\begin{array}{lccccccc}\text { Tube } & \text { A } & \text { B } & \text { C } & \text { D } & \text { E } & \text { F } & \text { G } \\ & \text { I } 5 & \cdot \text { I } & \text { O75 } & \text { O5 } & \text { O2 } & \text { OI } & \text { O05 cc. } \\ \text { Result } & + & + & + & ++ & ++ & + & -\end{array}$

After incubation for twenty-four hours there was agglutination deposit in all the tubes above $G$, but there was a marked increase of opacity of the supernatant fluid going from ${ }^{*} \mathrm{C}$ to $\mathrm{A}$, i.e., with the greater amount of serum. The only tubes where the supernatant fluid cleared were $\mathrm{D}$ and $\mathrm{E}$. After incubating for a total of four days all the tubes $\mathrm{A}, \mathrm{B}$, and $\mathrm{C}$ showed clearing. Emulsion controls, it should be noted, remained unchanged, i.e., were not sedimented. It was considered at the time that as the most outstanding feature was the failure to sediment the cause might be physical, and that the sedimentation did not occur because of the increased viscosity in the tube due to the large amount of serum. In view of the further experiment detailed above in Table II., and of the mention by Hewlett of a similar phenomenon of a zone of inhibition with M. melitensis, no suggestion as to the cause is offered. No opportunity of consulting the work referred to by Hewlett has been possible, but the phenomenon, in the main, seems parallel. 
The phenomenon is of importance in that an apparent falling off in the agglutinating power of a serum does not necessarily mean that the end-point is to be expected in the next tube. There may be a zone of lessened agglutination, and then a further increase may be met before the end-point of agglutination reaction. This "endpoint" of reaction figure is important in contagious abortion, as it affords a means of comparing an animal's condition from time to time as regards the progress of the disease.

\section{(c) Optimum Amount of Emulsion to Use.}

Having determined the points referred to earlier in this paper, the question of optimum quantity of bacterial emulsion naturally arises.

Here, again, there being no universal standard adopted, observers cannot strictly compare their results. Thus, to say that an animal $05 \mathrm{cc}$. of whose serum produces agglutination should be considered as affected in reality conveys no definite meaning in view of the experiments in sub-sections $(a)$ and $(b)$ above, unless the amount of emulsion be stated at the same time. On the other hand, workers find by experience what is a convenient quantity of emulsion to use, based on the size of the tubes employed, etc., and having found this amount retain it as a standard and use it in future; their own results, therefore, are strictly comparable with one another, but not with those of other workers.

The following experiments were made to determine what quantity, allowing for ease of reading after twenty-four hours' incubation, was suitable to use.

Material.-Serum from cow (as used in previous tests); emulsion (standardised $=\mathrm{IO} X$.).

Four sets of tubes, numbered I., II., III., IV., were put up, using a different quantity of serum in each set. Each set consisted of four tubes-A, B, C, and D-and the quantity of emulsion used was :-

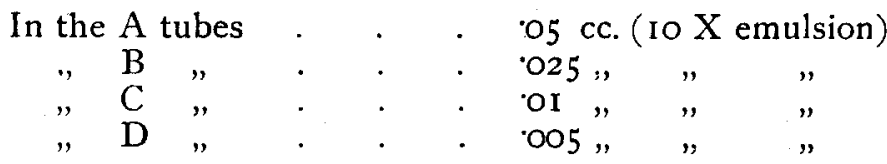

To Set I. was added I cc. diluted serum (equal to 02 cc. pure serum), and carbolised saline was added to make the total volume 2 cc.

To Set II. was added 5 cc. diluted serum (equal to $O$ I cc. pure serum), and carbolised saline was added to make the total volume $2 \mathrm{cc}$.

To Set III. was added 25 cc. diluted serum (equal to $005 \mathrm{cc}$. pure serum), and carbolised saline was added to make the total volume $2 \mathrm{cc}$.

To Set IV. was added I cc. diluted serum (equal to 02 cc. pure serum), and carbolised saline was added to make the total volume $20 \mathrm{cc}$.

Controls.--Serum controls were put up, and remained unchanged.

Emulsion-control tubes, of each quantity of emulsion used with carbolised saline added, were put up and remained unchanged. 
Sets I., II., and III. were read at the end of twenty-four hours' incubation, the result being :-

\begin{tabular}{|c|c|c|c|c|}
\hline Emulsion. & $\begin{array}{c}\mathrm{A} \\
.05 \mathrm{cc} .\end{array}$ & $\begin{array}{c}\mathrm{B} \\
.025 \mathrm{cc} .\end{array}$ & $\begin{array}{c}\mathrm{C} \\
\cdot 0 \mathrm{I} \mathrm{cc} .\end{array}$ & $\begin{array}{c}\mathrm{D} \\
.005 \mathrm{cc} .\end{array}$ \\
\hline $\begin{array}{l}\text { Set I. (Containing pure serum, } \\
.02 \mathrm{cc} \text { ) }\end{array}$ & + & + & + & + \\
\hline $\begin{array}{l}\text { Set II. (Containing pure serum, } \\
\text { oI cc.) }\end{array}$ & + & + & + & + \\
\hline $\begin{array}{l}\text { Set III. (Containing pure serum, } \\
.005 \mathrm{cc} .)\end{array}$ & - & + & + & + \\
\hline Set IV. (Containing pure serum, & + & + & + & $?$ \\
\hline
\end{tabular}

Note.-Set IV, at the end of twenty-four hours' incubation showed positive agglutination with $05 \mathrm{cc}$. of emulsion, i.e., in tube $\mathrm{A}$, but not in the other tubes- $B, C, D$.

In tubes $\mathrm{B}$ and $\mathrm{C}$, containing $\mathrm{O} 25$ and $\mathrm{O}$ ( $\mathrm{cc}$. emulsion, a positive agglutination was manifest at the end of three days' incubation, but the deposit in tube D, with $005 \mathrm{cc}$. emulsion, even at the end of this time, was very small indeed, in fact just appreciable.

The controls, it should be mentioned, remained unchanged.

From these experiments it appears as if the large volume of fluid $(20 \mathrm{cc}$.) in Set IV. affected the rate of sedimentation of the clumps of bacilli in those tubes with the smaller quantities of emulsion. As, however, such a large quantity of fluid is not used in the tubes in making a diagnostic test, these results in Set IV. are not of great importance.

In the practical application of the test the total volume of fluid in each tube is usually made up to about $\mathrm{I} \cdot 5 \mathrm{cc}$.

A number of tests have been made in which the total amount was $2 \mathrm{cc}$.

The tubes in Sets I., II., and III., where the total volume has been made up to $2 \mathrm{cc}$, , are therefore of primary importance. Here it is found that such a quantity of emulsion and of total fluid have been employed that the complete agglutination reaction takes place within the first twenty-four hours.

Tubes of 2.5 cc. capacity have been found very suitable in making the test, and the amounts of diagnostic material (serum, whey, etc.) and of emulsion are, even over a large range of quantities, but involving only a few different basal dilutions, easily contained in 1.5 or $2 \mathrm{cc}$. of fluid. Also twenty-four hours is a convenient time for incubation before reading the results.

Where the total volume of fluid in each tube is made up to $I^{\prime} 5$ or $2 \mathrm{cc}$., and with incubation extending over eighteen to twenty-four hours, the optimum of emulsion will be the smallest quantity which gives results that are easily read, whether the agglutination reaction be positive or negative. 
The deposit following agglutination should be such that it can be easily distinguished by the naked eye, even though, as is frequently the case, the whole of the organisms be not sedimented.

In the absence of deposit, i.e., in a negative agglutination reaction, there should be such a quantity of emulsion that a tube containing it can be easily distinguished from a tube not containing any emulsion.

It is of interest here to note the naked-eye appearance of the emulsion controls to the sets of tubes under review.

In four of these controls the total volume of fluid was made up to $2 \mathrm{cc}$. with carbolised saline, in the other four to $20 \mathrm{cc}$.

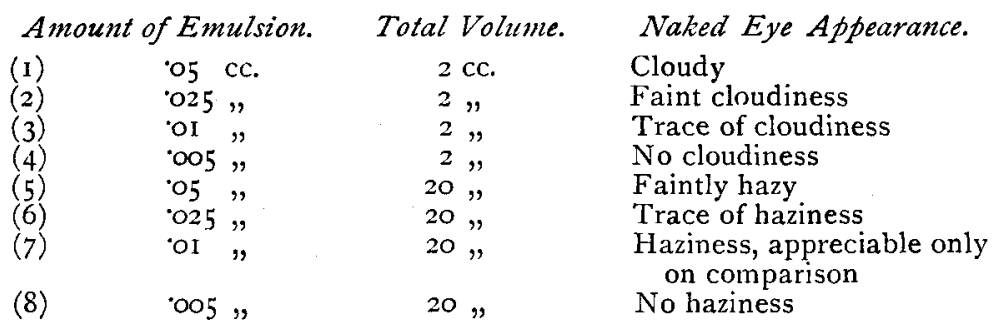

Of those emulsion controls containing $2 \mathrm{cc}$. of total fluid, it will be seen that (I) and (2) above possess such a degree of cloudiness that they are readily distinguishable to the naked eye as containing emulsion. These tubes contain $05 \mathrm{cc}$. and $025 \mathrm{cc}$. respectively.

In Sets I., II., and III. of agglutination results recorded above, the smallest deposit (positive agglutination) which is easily read (tubes containing $2 \mathrm{cc}$. of fluid) is that where there is $025 \mathrm{cc}$. of emulsion.

In Set IV. the only tube in which (although there was the same quantity of serum in each tube) agglutination was manifest in twenty-four hours was that one in which there was 05 cc. of emulsion in the tube.

With this large volume of fluid ( $20 \mathrm{cc}$.) no smaller quantity gave a completed reaction in twenty-four hours.

From these experiments, therefore, it has been concluded that the optimum amount of emulsion to use is $05 \mathrm{cc}$. of "Standard Io X" emulsion (or $5 \mathrm{cc}$. of "Standard X" emulsion).

This amount, $5 \mathrm{cc}$. of "Standard X" emulsion, has therefore been adopted for use in all practical diagnostic tests for the reasons that (I) it gives a marked naked eye deposit (and hence is easily read) in a positive reaction; (2) conversely, it gives a definitely cloudy appearance (and hence is easily read) in a tube where there is no agglutination; (3) with the total volume of fluid in the tube anything from $\mathrm{I} .5 \mathrm{cc}$. to $20 \mathrm{cc}$., the agglutination reaction is complete in twenty-four hours ; (4) it is the minimum amount of emulsion that will answer the above requirements.

In conclusion I wish to express my best thanks to Professor H. H. Woodruff, Director of the Institute, for permission to undertake this work, and for much kindly help and advice. 


\section{BIBLIOGRAPHY.}

(1) M'Fadyean and Stockman (I 909): Report of Departmental Committee (Board of Agriculture, Great Britain) on Epizootic Abortion, Part I.

(2) Mohler and Traum (1913): Annual Report, Bureau of Animal Industry, Department of Agriculture, U.S.A., I 9 I I, pp. I47-183.

(3) M'Fadyean and Stockman (I9I2): Journal of Comparative Pathology and Therapeutics, Vol. XXV., I 9 I 2, pp. 22-29.

(4) M'Farland: Journal, American Medical Association, Vol. XLIV., p. I 176. Extracted in Bulletin de L'Institut Pasteur, Vol. VI., 1908, p. I 23.

(5) Hewlett (r904): Manual of Bacteriology, Fifth Edition, p. r88.

\section{A CASE OF LYMPHO-SARCOMA IN THE HORSE: ARTERIOSCLEROTIC CHANGES IN HEART AND LUNGS*}

By A. E. MetTam, M.R.C.V.S., B.Sc., Royal Veterinary College of Ireland, Dublin.

I received from Major $H$. M. Lenox-Conyngham, A.V.C., the spleen, heart, and lungs of a horse belonging to the I6th Lancers, at that time stationed at the Curragh.

The history of the case is briefly as follows (I quote from Major Conyngham's letter):-

"The horse was only eight years old. It was first noticed to be ailing about six months ago, the symptoms being slight loss of animation and a most peculiar dull vacant expression of the eyes. No definite diagnosis was made and it was not thought serious. It was kept at work and even hunted a few times up to a month ago, when it grew suddenly worse and steadily got thinner and weaker and developed a most extraordinary shape-neck and everywhere where muscle should be, became thin to scragginess, but its abdomen became more and more distended like a 'hoven' cow. It was given purgatives more than once, but no ordinary dose had the slightest effect. Besides the organs sent you the post-mortem showed about a gallon of straw-coloured fluid in the abdominal cavity. Mesenteric glands enlarged and soft, liver fatty, left kidney congested."

The organs I received showed the following :-

Spleen.-The spleen was enormous, or appeared so, but on close examination it was found that it had been invaded by what was apparently a new growth, and that there could still be traced portions of the organ unaltered and uninfiltrated. Spleen and growth formed a compact mass, firm on handling, and weighing altogether 43 lbs. On cutting into the growth it was found to be of a dead white colour; parts of it were necrosed and others again had undergone mucoid degeneration. Generally the tumour mass was soft and non-resistant, but the consistency or resistance varied in places. The closest inspection showed no trace of tubercles, no caseation, no calcification, none of the mortar-like caseous material seen in the lesions of tuberculosis of the spleen in equines. No tubercle bacilli could be found on the examination of several smears appropriately stained, and there was no reason to suspect tubercle 